\title{
Influência dos metais pesados no acometimento do câncer: Uma revisão da literatura
}

\author{
Influence of heavy metals on cancer accommodation: A literature review \\ Influencia de los metales pesados en la causa del câncer: Una revisión de la literatura
}

Recebido: 11/05/2021 | Revisado: 17/05/2021 | Aceito: 20/05/2021 | Publicado: 06/06/2021

\author{
Jessica Valéria Bastos Cruz \\ ORCID: https://orcid.org/0000-0002-1688-7393 \\ Unidade de Ensino Superior de Feira de Santana, Brasil \\ E-mail: jessicabastos.bio@gmail.com \\ Érica Pereira dos Santos \\ ORCID: https://orcid.org/0000-0003-1988-6721 \\ Unidade de Ensino Superior de Feira de Santana, Brasil \\ E-mail: santospereiraerica17@gmail.com \\ Natália de Jesus Silva \\ ORCID: https://orcid.org/0000-0002-4341-8859 \\ Unidade de Ensino Superior de Feira de Santana, Brasil \\ E-mail: natyvariedades1@hotmail.com \\ Felicson Leonardo Oliveira Lima \\ ORCID: https://orcid.org/0000-0001-5256-6768 \\ Universidade Estadual de Feira de Santana \\ E-mail: felicsonleonardo@hotmail.com \\ Priscila Pimentel Martinelli \\ ORCID: https://orcid.org/0000-0002-5287-2586 \\ Unidade de Ensino Superior de Feira de Santana, Brasil \\ E-mail: priscilamartinellibiomed@gmail.com \\ João Ronaldo Tavares de Vasconcellos Neto \\ ORCID: https://orcid.org/0000-0001-6280-538X \\ Unidade de Ensino Superior de Feira de Santana, Brasil \\ Universidade Estadual de Feira de Santana, Brasil \\ E-mail: jrtvasconcellosneto@gmail.com
}

\begin{abstract}
Resumo
Objetivo: Relatar a influência dos metais pesados no acometimento do câncer, descrevendo assim, os principais metais detentores dessa possibilidade, citando ainda, os tipos de cânceres comumente ocasionados pela exposição a esses metais. Metodologia: Trata-se de uma revisão da literatura de natureza descritiva e qualitativa acerca da influência dos metais pesados no acometimento do câncer. O estudo foi realizado no período de dezembro de 2020 a fevereiro de 2021, mediante análise nas bases de dados: Pubmed, SciELO e Lilacs. A busca e seleção dos materiais foram realizadas baseando-se em critérios de inclusão e exclusão previamente estabelecidos, o que totalizou 48 materiais, estes publicados entre os anos de 2000 a 2021, compondo assim o presente estudo. Resultados e discussão: Mesmo em baixas concentrações, a exposição exacerbada aos metais pesados promove inflamação crônica, o que desencadeia o estresse oxidativo, e subsequentemente, o processo de carcinogênese. Dentre os principais metais envolvidos no processo de carcinogênese, pode-se citar: o cobre, mercúrio, cobalto, níquel, cádmio, cromo, arsênio, prata e o chumbo. No que se remete aos tipos de cânceres acometidos pela exposição continuada a esses metais, temse: os cânceres de pulmão, pele, ovário, mama, estômago, próstata, cérebro e laringe. Conclusão: Os metais pesados apresentam grande influência no processo de carcinogênese, o que está intrinsicamente vinculado a exposição sequenciada e bioacumulação destes elementos. Numerosos são os metais pesados com o potencial de desencadear o desenvolvimento de canceres, o que reflete na variabilidade de tecidos e órgãos afetados e a diversidade de tumores aos seres humanos.
\end{abstract}

Palavras-chave: Influência; Metais pesados; Câncer.

\begin{abstract}
Objective: To report the influence of heavy metals in the onset of cancer, thus describing the main metals that hold this possibility, also citing the types of cancers commonly caused by exposure to these metals. Methodology: This is a literature review of a descriptive and qualitative nature about the influence of heavy metals on cancer. The study was carried out from December 2020 to February 2021, by analyzing the databases: Pubmed, SciELO and Lilacs. The search and selection of materials were carried out based on previously established inclusion and exclusion criteria, which totaled 48 materials, these published between the years 2000 to 2021, thus composing the present study. Results and discussion: Even in low concentrations, exacerbated exposure to heavy metals promotes chronic inflammation, which triggers oxidative stress, and subsequently the process of carcinogenesis. Among the main
\end{abstract}


metals involved in the carcinogenesis process, we can mention: copper, mercury, cobalt, nickel, cadmium, chromium, arsenic, silver and lead. Regarding the types of cancers affected by continued exposure to these metals, there are: lung, skin, ovary, breast, stomach, prostate, brain and larynx cancers. Conclusion: Heavy metals have a great influence on the process of carcinogenesis, which is intrinsically linked to sequenced exposure and bioaccumulation of these elements. Numerous are heavy metals with the potential to trigger the development of cancers, which reflects in the variability of tissues and organs affected and the diversity of tumors in humans.

Keywords: Influence; Heavy metals; Cancer.

\begin{abstract}
Resumen
Objetivo: Informar la influencia de los metales pesados en la aparición del cáncer, describiendo así los principales metales que tienen esta posibilidad, citando también los tipos de cánceres comúnmente causados por la exposición a estos metales. Metodología: se trata de una revisión de la literatura de carácter descriptivo y cualitativo sobre la influencia de los metales pesados en el cáncer. El estudio se realizó de diciembre de 2020 a febrero de 2021, mediante el análisis de las bases de datos: Pubmed, SciELO y Lilacs. La búsqueda y selección de materiales se realizó en base a criterios de inclusión y exclusión previamente establecidos, los cuales totalizaron 48 materiales, estos publicados entre los años 2000 a 2021, componiendo así el presente estudio. Resultados y discusión: Incluso en concentraciones bajas, la exposición exacerbada a metales pesados promueve la inflamación crónica, que desencadena el estrés oxidativo y, posteriormente, el proceso de carcinogénesis. Entre los principales metales involucrados en el proceso de carcinogénesis, podemos mencionar: cobre, mercurio, cobalto, níquel, cadmio, cromo, arsénico, plata y plomo. En cuanto a los tipos de cánceres afectados por la exposición continua a estos metales, se encuentran: cánceres de pulmón, piel, ovario, mama, estómago, próstata, cerebro y laringe. Conclusión: Los metales pesados tienen una gran influencia en el proceso de carcinogénesis, que está intrínsecamente ligado a la exposición secuenciada y bioacumulación de estos elementos. Numerosos son los metales pesados con el potencial de desencadenar el desarrollo de cánceres, lo que se refleja en la variabilidad de los tejidos y órganos afectados y la diversidad de tumores en los seres humanos.
\end{abstract}

Palabras clave: Influencia; Metales pesados; Cáncer.

\title{
1. Introdução
}

Os metais pesados representam elementos quimicamente reativos os quais podem ocasionar processos de bioacumulação e toxicidade ao organismo, uma vez que este se torna incapaz de eliminar tais substâncias. Salienta-se ainda, que a contaminação por meio destas substâncias age de forma silenciosa provocando efeitos nocivos ao homem, as chamadas neoplasias (Leite et al., 2015; Ferron et al., 2020).

É importante dizer que tais compostos interferem intrinsecamente na manutenção da homeostasia celular e estes podem gerar efeitos acumulativos prejudiciais ao homem se expostos de forma acentuada, como é o caso do alumínio, cobre, zinco e mercúrio, onde podem favorecer lesões no sistema nervoso central. Dentre as fontes potenciais de exposição a esses metais estão incluídas as fontes naturais, como as águas subterrâneas e minérios metálicos, além de produtos comerciais, remédios, alimentos contaminados e insumos dos processos industriais (Zendron, 2015; Peixoto \& Asmus, 2020).

Ressalta-se ainda, que a absorção dos metais pesados no organismo, seja por meio da água potável e dos alimentos ou até mesmo por meio do ar, cursa com a formação de mecanismos celulares que acabam por inativar e/ou alterar os sistemas enzimáticos, desencadeando uma perturbação e morte celular. Com relação à natureza e gravidade inerente à toxicidade, estas sofrem variações de acordo com o metal pesado implicado, bem como os seus níveis de exposição química e estados de valência, além do modo que decorre tal exposição, sendo esta aguda ou crônica, bem como outros fatores, que incluem a idade do indivíduo e o tempo de exposição (Sharma et al., 2014).

Mesmo em baixas concentrações, tais substâncias podem influenciar de forma irreversível na fisiologia e bioquímica da célula. Ademais, alguns metais pesados já são classificados como cancerígenos humanos, onde a exposição exacerbada eleva-se a incidência de uma inflamação crônica, o que por sua vez, passa a desenvolver um estresse oxidativo (acúmulo de radicais livres), sendo este, importante fator para desencadear o desenvolvimento tumoral no processo de carcinogênese (Koedrith \& Seo, 2011; Martinez-Zamudio, 2011; Caserta et al., 2013; Leite et al., 2015).

Deste modo, esses compostos acabam prejudicando toda a saúde humana, propiciando o estresse oxidativo a nível 
celular, além de agravos neurológicos, bem como lesões ao nível do DNA, atuando ativamente no metabolismo da glicose, gerando alterações, as quais acabam interferindo diversos processos primordiais, como o sistema de reparação do DNA, ocasionando uma alteração genômica, bem como a interrupção do crescimento e proliferação celular, atuando na desregulação de oncogenes ou genes supressores de tumores. Sendo assim, toda a genotoxicidade e a mutagenicidade permeado por esses metais acabam estimulando na produção de espécies reativas de oxigênio (EROS) e espécies reativas de nitrogênio (RNS) (Koedrith \& Seo, 2011; Leite et al., 2015; Neves, 2015).

Diante do exposto, o presente estudo objetivou relatar a influência dos metais pesados no acometimento do câncer, descrevendo assim, os principais metais detentores dessa possibilidade, citando ainda, os tipos de cânceres comumente ocasionados pela exposição a esses metais.

\section{Metodologia}

Salienta-se que, a revisão de literatura tem papel fundamental no trabalho acadêmico, uma vez que, a produção de conhecimento não é um processo isolado, mas sim, continuado de busca. Desta forma, ela permite que a cada nova investigação, seja inserido análises completando ou contestando contribuições acerca da temática. Além do mais, a pesquisa qualitativa, possui grande relevância também, pois permite a interpretação de um fenômeno em observação, bem como a análise, descrição e compreensão de determinado fato, a fim de entender o seu respectivo significado (Freitas, 2016).

O Presente estudo trata-se de uma revisão da literatura de natureza descritiva e qualitativa, acerca da influência dos metais pesados no acometimento do câncer. O estudo foi realizado no período de dezembro de 2020 a fevereiro de 2021, mediante análise nas bases de dados: Pubmed, SciELO e Lilacs. Para tanto, foram utilizados os descritores na língua portuguesa: "Influência”, "Metais Pesados", “Câncer”; língua inglesa: "Influence”, "Heavy metals", "Cancer”; e espanhola: "Influencia", "Metales pesados", "Cáncer", sendo que estes foram previamente buscados no DeCS (Descritores em Ciências da Saúde).

Para a busca e seleção dos materiais, critérios de inclusão e exclusão foram pré-estabelecidos. Adequaram-se aos critérios de inclusão, conteúdos que abordavam a temática proposta, redigidos em português, inglês ou espanhol e disponibilizados na íntegra (versão online). Os critérios de exclusão foram aplicados, aos estudos publicados em línguas diferentes das listadas, duplicados, indisponíveis na versão online e com discrepância entre os objetivos e o conteúdo abordado.

Inicialmente, por meio da busca utilizando os termos nas plataformas já citadas, 2.341 artigos foram encontrados, posterior a isso, a análise dos materiais foi empregada, mediante avaliação dos títulos e resumos para verificação de quais vinculavam-se ao tema desta revisão, sendo selecionados 470 artigos, visto que muitos estavam duplicados, apresentavam discrepância de informações, ou não atendiam aos idiomas pré-estabelecidos. Subsequente a esta etapa, 301 artigos foram eliminados, por estarem indisponíveis na íntegra, destes 169 artigos foram lidos na íntegra, o que ao fim, sumarizou-se em apenas 48 artigos, estes publicados entre os anos de 2000 a 2021.

\section{Resultados e Discussão}

\subsection{Metais pesados e inferências no organismo}

A designação de "metais pesados" está relacionado aos elementos metálicos cuja densidade é superior a $5 \mathrm{~g} / \mathrm{cm} 3$, sendo estes capazes de corroborar na formação de sulfuretos. Dentre os metais pesados mais conhecidos está o chumbo $(\mathrm{Pb})$, crômio $(\mathrm{Cr})$, prata $(\mathrm{Ag})$, níquel $(\mathrm{Ni})$, ferro $(\mathrm{Fe})$, arsênio (As), cobalto $(\mathrm{Co})$, cádmio $(\mathrm{Cd})$, zinco $(\mathrm{Zn})$. Ademais, de acordo com as propriedades químicas dos metais pesados, está o elevado nível de reatividade, além de gerar processos como a 
bioacumulação, o que reflete serem grandes potenciais de ocasionar inúmeras reações químicas das quais não são metabolizáveis pelo organismo (Souza et al., 2018).

Para Leite et al., (2015) e Da Cruz \& Gonçalves (2020), a definição de metais pesados está relacionada a sua elevada massa atômica, sendo inclusos neste grupo o arsênio (As), berílio $(\mathrm{Be})$, cádmio $(\mathrm{Cd})$, cromo $(\mathrm{Cr})$, chumbo $(\mathrm{Pb})$, manganês (Mn), mercúrio (Hg), níquel (Ni) e selênio (Se). Destes, o $\mathrm{As}, \mathrm{Pb}, \mathrm{Cd}, \mathrm{Hg}$, são apontados como as principais ameaças para a saúde humana. Estes metais estão contidos na natureza, e mesmo em concentrações diminuídas, influem irreversivelmente nos processos bioquímicos e fisiológicos dos indivíduos, culminando em lesões ou morte, para humanos, animais ou plantas. A exposição aos metais pesados pode provocar no homem: estresse oxidativo, lesões neurológicas, agravos ao DNA, modificações no metabolismo da glicose e do cálcio, além de interferências sob alguns elementos essenciais.

Souza et al., (2018) alertam que o excesso de metais pesados no organismo pode contribuir não somente para que se formem radicais livres, mas também de espécies reativas do oxigênio (ERO), ocasionando assim, no estresse oxidativo nos organismos vivos. Neste sentido, torna-se evidente que, devido a acumulação de tais elementos, os organismos acabam desenvolvendo inúmeros sistemas antioxidantes para sua defesa, objetivando proteção contra as consequências advindas das ERO, como por exemplo, a sua ação mutagênica.

De acordo com Caserta et al., (2013) e Leite et al., (2015) a exposição ambiental e ocupacional aos metais, pode relacionar-se com o aparecimento de diversas doenças a nível do sistema imunológico, pulmonar, renal, neurológico, endócrino, além do sistema reprodutor e cardiovascular. Salienta-se que, o fator mais importante para que se retenha o material no organismo é a sua semivida biológica (decorrência de tempo em que o organismo demora para excretar metade da dose tóxica absorvida), o que depende do tecido ou órgão onde o metal está contido. Sendo assim, tal exposição sistemática a estas substâncias acaba sendo grande potencial de processos inflamatórios crônicos.

Deste modo, Kumar et al., (2011), apontam que o primeiro meio de defesa do organismo em resposta a tal exposição, é a inflamação, o que objetiva evitar os efeitos oriundo do estresse. Neste processo acaba ocorrendo várias reações das quais englobam a destruição tecidular por meio de células inflamatórias, infiltração de células mononucleares, além da angiogênese e eventos fibróticos.

Caserta et al., (2013) e Leite et al., (2015) destacam, que em pequenas quantidades alguns metais se apresentam como nutrientes essenciais (elementos essenciais) para que se tenha uma vida saudável, tais elementos encontram-se de forma natural em certos alimentos como frutos do mar, frutas e legumes. No entanto, existem ainda, os elementos micro-contaminantes que dependendo da sua concentração, podem atuar com toxicidade.

\subsection{Carcinogênese induzida por metais}

A observação do desenvolvimento de canceres nos seres humanos a partir da exposição a substancias contidas no ambiente é antiga. Em meados do século XVIII, já haviam relatos da ocorrência de câncer de escroto em limpadores de chaminés mediados pela exposição ao alcatrão e a fuligem. Caracteriza-se como carcinogênese, os processos que culminam na conversão de uma célula normal em maligna. Os carcinógenos, por sua vez, são os agentes indutores desse processo. No geral, para que haja o desenvolvimento de um tumor maligno, requer-se a exposição sequenciada ao carcinógeno (Loureiro et al., 2002; Brey et al., 2020).

Guecheva (2002) em consonância com Paula (2016) retratam que o potencial de genotoxicidade promovida pelos íons de metais pesados decorre de dois mecanismos. O primeiro mediado pela interferência com o reparo e replicação do DNA e o segundo, pela geração de danos oxidativos diretos ou por via ERO (Espécies reativas de oxigênio). As lesões ocasionadas por este processo são corriqueiramente recompostas pelas células, entretanto, algumas perduram ou são erroneamente reparadas.

Para Koedrith e Seo (2011) e Martinez-Zamudio e Ha (2011) embora os mecanismos que envolvem a formação de 
tumores em consequência da exposição aos metais pesados ainda não sejam totalmente esclarecidos, os mesmos apontam o estresse oxidativo como mecanismo crucial para o desenvolvimento tumoral.

Düsman et al., (2012) e Koller e Reginato (2017) apontam que a totalidade dos metais carcinogênicos promovem aumento significativo dos efeitos mutagênicos e citotóxicos nas células mamíferas, em consonância aos vários tipos de agentes que danificam o DNA. A exposição sequenciada a determinados metais, desencadeia processos inflamatórios crônicos, o que resulta no estresse oxidativo e carcinogênese. O acúmulo de danos oxidativos ao DNA é descrita como a causa principal de doenças neurodegenerativas, artrite reumatoide, problemas cardíacos, esclerose amiolateral e o câncer, bem como o processo do envelhecimento.

Leite et al., (2015) afirmam que o acúmulo de radicais livres resulta no estresse oxidativo, este acumulo, promove desequilíbrio entre a capacidade do sistema em eliminar intermediários reativos e a produção dos radicais, dando gatilho assim, para a carcinogênese. Os íons metálicos possuem propriedades semelhantes aos íons essenciais, deste modo, acontece uma competição entre os locais de ligação biológicos, perturbando a estrutura celular, as funções biomoleculares e a homeostasia do metal. Deste modo, o mecanismo de carcinogênese induzida por metais pode ser abreviado em: (a) estímulo para o estresse oxidativo e a lesões nos componentes celulares, principalmente o DNA; (b) inferência sob os sistemas de reparo do DNA, o que resulta na instabilidade genômica; (c) interferência no crescimento e na proliferação celular por meio das vias de sinalização; e (d) desregulação de genes supressores de tumores (oncogenes).

De acordo com Brasil, (2013) e Cameron et al., (2011) os metais pesados acabam por provocarem a carcinogênese, e este se dá na grande maioria das vezes pela inalação. A via pulmonar favorece o processo de toxicidade aos principais órgãos como os rins, fígado, coração, os próprios pulmões e outros. Ressalta-se que, muitos compostos são genotóxicos e apresentam elevada potencialidade para corroborar em alterações genéticas em tecido-alvo. Desta forma, esse processo ocorrendo em proto-oncogenes e genes supressores tumorais, aos quais atuam no controle do crescimento ou até mesmo na diferenciação das células, estes acabam por favorecer no desenvolvimento de câncer nesses órgãos-alvos.

Koedrith e Seo (2011) também verificaram que os metais pesados podem gerar processos de carcinogênese e que este se dá por meio de mecanismos como o ataque oxidativo, reparo de DNA, vias de transdução de sinal particulares e homeostase redox celular. Tais observações acabam fornecendo evidências de que fatores reguladores emergentes em resposta a certo estresse oxidativo e proteínas de reparo de DNA constituem fatores que predizem o início da progressão de um tumor.

Ainda, segundo Lee e colaboradores (2012) os metais pesados podem influenciar diretamente na geração de mediadores que atuarão não somente em transcrição nuclear e proteínas de sinalização, mas também em danos no DNA com consequente interrupção celular atuando na alteração do equilíbrio de oxirredução celular, aumentando o número de espécies reativas de oxigênio, constituindo um dos principais mecanismos da carcinogênese.

Neste sentido, Kuno et al., (2010), bem como Kim e Lee, (2012) afirmam que a exposição ambiental a metais pesados e sua introdução no organismo, até mesmo em baixos níveis, constitui um grave problema de saúde pública, devido à ausência de concentração que seja inofensiva e em razão de seu potencial acumulativo no corpo humano, sendo assim, uma vez no sistema corporal, esses metais acabam mantendo-se por longo período, resultando em grandes consequências à saúde. A Tabela 1 demonstra os principais metais pesados com possibilidade de ocasionar canceres. 
Tabela 1: Metais pesados detentores de potencial de carcinogênese.

\begin{tabular}{|c|c|c|c|}
\hline Autor/Ano & Título & Metal & Descrição \\
\hline $\begin{array}{c}\text { Guecheva } \\
\text { (2002) }\end{array}$ & $\begin{array}{l}\text { Avaliação do potencial } \\
\text { tóxico e genotóxico do } \\
\text { sulfato de cobre em } \\
\text { planária: utilidade deste } \\
\text { organismo para } \\
\text { biomonitoramento } \\
\text { ambiental }\end{array}$ & Cobre & $\begin{array}{c}\text { Estudo que avaliou o potencial de } \\
\text { toxicidade e genotoxicidade do cobre e seu } \\
\text { biomonitoramento ambiental. Relatando } \\
\text { assim, a possibilidade de desenvolvimento } \\
\text { de cânceres, por meio da exposição ao } \\
\text { cobre. }\end{array}$ \\
\hline $\begin{array}{l}\text { Pavlogeorgatos } \\
\qquad(2002)\end{array}$ & $\begin{array}{l}\text { The Importance of } \\
\text { Mercury Determination } \\
\text { and Speciation to the } \\
\text { Health of the General } \\
\text { Population }\end{array}$ & Mercúrio & $\begin{array}{l}\text { O efeito tóxico do mercúrio no organismo } \\
\text { se dá, pela sua capacidade de interferir em } \\
\text { reações metabólicas enzimáticas. A } \\
\text { absorção do mercúrio metálico, } \\
\text { principalmente na forma de vapor pela via } \\
\text { inalatória, o que pode resultar em uma } \\
\text { variedade de efeitos orgânicos, dentre eles, } \\
\text { anomalias cromossômicas e o câncer. }\end{array}$ \\
\hline $\begin{array}{l}\text { Alves \& Della-Rosa } \\
\qquad(2003)\end{array}$ & $\begin{array}{l}\text { Exposição ocupacional ao } \\
\text { cobalto: aspectos } \\
\text { toxicológicos }\end{array}$ & Cobalto & $\begin{array}{l}\text { O estudo retrata a recorrência de casos de } \\
\text { câncer em ensaios experimentais com } \\
\text { animais de laboratório, os quais } \\
\text { demonstram que injeções intramusculares, } \\
\text { subcutâneas ou intraperitoneais, de pó de } \\
\text { Cobalto (Co) ou compostos do Co, podem } \\
\text { induzir a produção de tumores. }\end{array}$ \\
\hline $\begin{array}{l}\text { Cameron et al., } \\
\qquad(2011)\end{array}$ & $\begin{array}{c}\text { Mecanismos de } \\
\text { Genotoxicidade Induzida } \\
\text { por Níquel e } \\
\text { Carcinogenicidade }\end{array}$ & Níquel & $\begin{array}{c}\text { O estudo demonstrou que o Níquel } \\
\text { favorece genotoxicidade, apresentando-se } \\
\text { como cancerígeno. }\end{array}$ \\
\hline $\begin{array}{l}\text { Lubovac-Pilav et al., } \\
\qquad(2013)\end{array}$ & $\begin{array}{l}\text { Perfil de expresso para } \\
\text { entender os efeitos da } \\
\text { exposição crônica ao } \\
\text { cádmio em células de } \\
\text { câncer de mama MCF-7 }\end{array}$ & Cádmio & $\begin{array}{l}\text { A exposição prolongada ao cádmio não } \\
\text { resulta apenas na desregulação dos genes, } \\
\text { mas em vários mecanismos distintos aos } \\
\text { quais estão envolvidos em processos de } \\
\text { apoptose, crescimento celular e, em } \\
\text { especial, no câncer de mama. }\end{array}$ \\
\hline $\begin{array}{c}\text { Da Costa et al., } \\
(2016)\end{array}$ & $\begin{array}{c}\text { Efeitos do cromo } \\
\text { hexavalente sobre o } \\
\text { crescimento de raízes e } \\
\text { ciclo celular no meristema } \\
\text { da ponta da raiz de Allium } \\
\text { cepa }\end{array}$ & Cromo & $\begin{array}{c}\text { Nesta investigação, o Cromo hexavalente é } \\
\text { caracterizado como cancerígeno para os } \\
\text { humanos, o que é elucidado pela Agência } \\
\text { Internacional de Pesquisa sobre Câncer } \\
\text { (IARC). }\end{array}$ \\
\hline $\begin{array}{l}\text { Silva \& Santos } \\
\qquad(2016)\end{array}$ & $\begin{array}{c}\text { Avaliação do Potencial } \\
\text { Risco à Saúde Humana de } \\
\text { Metais Pesados em Peixes } \\
\text { Marinhos }\end{array}$ & Arsênio & $\begin{array}{l}\text { O autor aponta o arsênio como um dos } \\
\text { metais pesados com maior probabilidade } \\
\text { para causar problemas no organismo, } \\
\text { destacando que o consumo desse metal em } \\
\text { grandes quantidades, pode contribuir para } \\
\text { o desenvolvimento do câncer. }\end{array}$ \\
\hline $\begin{array}{l}\text { Manrich et al., } \\
\qquad(2017)\end{array}$ & $\begin{array}{l}\text { Citotoxicidade causada } \\
\text { por nanomateriais: } \\
\text { avaliação do micronúcleo }\end{array}$ & Prata & $\begin{array}{l}\text { Nanopartículas e nanotubos de prata, bem } \\
\text { como outros tipos de materiais, foram } \\
\text { avaliados quanto ao seu potencial de } \\
\text { cancerosidade por meio do teste de } \\
\text { micronúcleo. Os resultados demonstraram } \\
\text { uma variedade de alterações } \\
\text { cromossômicas mediadas pela interação do } \\
\text { material com as células utilizadas. }\end{array}$ \\
\hline Guimarães et al., (2019) & $\begin{array}{l}\text { Estabelecimento de } \\
\text { agentes e atividades } \\
\text { ocupacionais } \\
\text { carcinogênicas prioritárias } \\
\text { para a vigilância em } \\
\text { saúde no Brasil }\end{array}$ & Chumbo & $\begin{array}{l}\text { Estudo que descreve a variedade de } \\
\text { agentes utilizados nas atividades } \\
\text { ocupacionais e apontados como } \\
\text { carcinogênicos. Tendo o chumbo como um } \\
\text { dos principais acometedores. }\end{array}$ \\
\hline
\end{tabular}

Fonte: Autores (2021). 
A presente tabela elucida os principais metais envolvidos no processo de carcinogênese, dentre os quais, o cobre é citado por Guecheva (2002), o mercúrio por Pavlogeorgatos (2002), cobalto, por Alves e Della-Rosa (2003), níquel, Cameron et al., (2011), cádmio, Lubovac-Pilav et al., (2013), cromo, Da Costa et al., (2016), arsênio, Silva e Santos (2016), prata, Manrich et al., (2017) e o chumbo Manrich et al., (2017).

Dentre os efeitos mais patogênicos ofertados pelos metais está na mutação do gene p53, ao qual está ligado à maioria dos cancros humanos. Além do mais, o fator nuclear de células T ativadas (NFAT) acaba controlando a produção de citocinas, o crescimento, bem como a diferenciação muscular e processos de angiogênese. Determinados metais podem também ativar o NFAT por meio de vias dependente de cálcio ou através da formação de peróxido de hidrogênio, além de ativar o HIF-1, o que promove o controle da homeostase do oxigênio através de inúmeros genes relacionados com o cancro, como por exemplo, o heme oxigenase i e o fator de crescimento do endotélio vascular (Koedrith \& Seo, 2011).

Thannickal e Fanburg (2000), Koedrith e Seo (2011) e Leite et al., (2015) ressaltam que alguns metais atuam em vias diversas, a exemplo, as proteínas denominadas de cinases ao serem ativadas por mitógenos MAPK-Mitogen-activated protein kinase. Este processo acaba promovendo a ativação de fatores que resultam em transcrição nuclear, como é o caso do Activator Protein-1, o AP-1, além do Nuclear factor of activated T-cells (NFAT), bem como do HIF-1, Hypoxia-inducible Factor-1, e dentre outros. Tais elementos acabam atuando na regulação da expressão de genes citoprotetores relevantes no processo de reparação do DNA, além de induzir a resposta imune, e também atuar na parada do ciclo celular e apoptose. Ademais, ressaltase que, o fator de transcrição nuclear AP-1 é essencial no crescimento celular e no processo de apoptose. Já em relação ao fator nuclear Nf-kb, exerce função significante, sendo essencial na resposta inflamatória, bem como na modificação e sobrevivência das células, no qual a sua ativação está ligada à carcinogênese.

Lee et al., (2012) deduzem que os metais cancerígenos elevam os níveis de ROS celulares por meio de diversos mecanismos, atuando como transdutor de sinal, ou até mesmo por meio da ativação de transdução de sinal sensível a redox vias, causando assim, problemas na expressão de genes que regulam uma série de mecanismos celulares. $O$ evento de estresse oxidativo pode afetar a regulação da expressão de genes por meio da ativação de aberrações na sinalização de moléculas importantes, o que reflete na carcinogênese induzida por metais. Além do mais, há uma modulação de outras moléculas atuantes na sinalização, incluindo o crescimento de receptores de fator (GF) e proteínas quinases.

\subsection{Tipos de câncer promovidos pela exposição aos metais pesados}

Conforme Silva e colaboradores (2019), os metais pesados podem acarretar na intoxicação de seres humanos, seja pelo contato direto, ingestão acidental ou por meio da cadeia alimentar, uma vez que tais compostos possuem a capacidade de bioacumulação o que afeta toda a cadeia mantendo concentrações maiores nos últimos níveis tróficos, que é o nível onde o ser humano se encontra. Salienta-se que as doses dessas substâncias podem ampliar-se no organismo, fornecendo assim, o risco no desenvolvimento de diversas neoplasias. A Figura 1 apresenta os principais tipos de cânceres mediados pela exposição aos metais pesados. 
Figura 1: Principais tipos de câncer ocasionados pela exposição aos metais pesados.

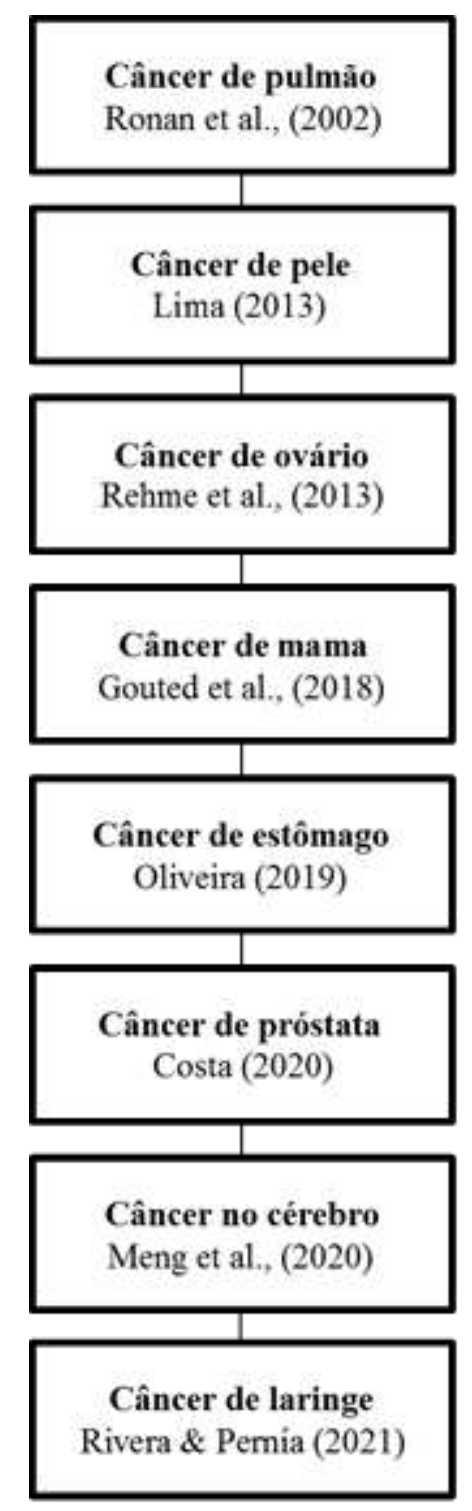

Fonte: Autores (2021).

A presente figura explana a grande variedade de cânceres que podem ser acometidos pela exposição continuada aos metais pesados. Dentre as possibilidades, Ronan et al., (2002) relata o câncer de pulmão, Lima (2013) câncer de pele, Rehme et al., (2013) câncer de ovário, Gouted et al., (2018) câncer de mama, Oliveira (2019) câncer de estômago, Costa (2020), câncer de próstata, Meng et al., (2020) câncer no cérebro e Rivera e Pernía (2021) câncer de laringe.

Para Perlroth e Branco (2017), a exposição materna a agentes químicos, em sua vasta abrangência, durante o período gestacional resultante da atividade industrial, agrícola ou da exploração de minerais, poderá refletir significativamente na prematuridade, podendo ainda causar nos filhos: malformações, distúrbios endócrinos, neurológicos e comportamentais, além de cânceres hematopoiéticos.

Chagas e colaboradores (2016) e Souza et al., (2018), explanam que a intoxicação pelo composto chumbo pode acarretar no desenvolvimento de células cancerígenas no estômago. O excesso de metais pesados pode danificar membranas, ácidos nucleicos, lipídios e outros componentes.

Parodi e colaboradores (2017), verificaram que o processo de carcinogênese permeado por metais, em especial o 
cádmio, favorece o aumento de células tronco progenitoras, sendo estes alvos de transformação maligna na mama corroborando no câncer mamário.

Lubovac-Pilav et al., (2014) descrevem que o cádmio consiste em um metaloestrógeno conhecido e este favorece a ativação do receptor de estrogênio promovendo o crescimento das células da mama provocando a desregulação de genes que atuam intimamente no desenvolvimento do câncer de mama.

Com relação aos metais pesados, Silva e Santos (2016) afirmam que estes podem gerar desde irritação no intestino, pulmão, estômago e pele, até o decréscimo na produção de eritrócitos e leucócitos, além de casos de hiperpigmentação e até mesmo o diabetes. Alerta-se que, o consumo de grandes quantidades de metais, como o arsênio pode contribuir para o desenvolvimento de câncer, em especial de pele, linfático, pulmão e fígado.

\section{Conclusão}

Mediante abordagens, conclui-se que os metais pesados apresentam grande influência sob o processo de carcinogênese, o que está intrinsecamente vinculado a exposição sequenciada e bioacumulação destes elementos. Os efeitos destes metais no organismo, promovem genotóxicidade e mutagenicidade, destinada principalmente ao gene p53, este por sua vez, demonstra relação com a grande maioria dos cancros em humanos.

Dentre a grande variedade de metais pesados, os estudos descrevem o arsênio, cádmio, chumbo e mercúrio como os principais causadores de câncer em humanos, seja por meio da exposição ambiental ou ocupacional. Em associação aos numerosos tipos de metais com propriedades tumorigênicas, pode-se mensurar os vários tipos de canceres promovidos por estes, os quais podem ser notados nas variadas etapas de vida dos seres humanos ou sexos, como o câncer de mama e ovários, ao sexo feminino, próstata, ao masculino ou hematopoiéticos na população infantojuvenil. Ainda assim, maiores pesquisas devem ser realizadas, destinando-se ao esclarecimento dos mecanismos destes metais ao corpo, além da investigação de outros tipos de metais e elementos, para avaliação do teor de carcinogênese.

\section{Referências}

Alves, A. N. L \& Della-Rosa, H. V. (2003). Exposição ocupacional ao cobalto: aspectos toxicológicos. Revista Brasileira de Ciências Farmacêuticas, 39(2), 129-139.

Barbosa, K. B. F., Costa, N. M. B., Alfenas, R. D. C. G., De Paula, S. O., Minim, V. P. R., \& Bressan, J. (2010). Estresse oxidativo: conceito, implicações e fatores modulatórios. Revista de nutrição, 23(4), 629-643.

Brasil. Ministério da Saúde. Diretrizes para a vigilância do câncer relacionado ao trabalho (2013). http://bvsms.saude.gov.br/bvs/publicacoes/diretrizes_vigilancia_cancer_relacionado_2ed.pdf.

Brey, C., Gouveia, F. T., Silva, B. S., Sarquis, L. M. M., Miranda, F. M. D. A., \& Consonni, D. (2020). Câncer de pulmão relacionado à exposição ocupacional: revisão integrativa. Revista Gaúcha de Enfermagem, 41.

Cameron, K. S., Buchner, V., \& Tchounwou, P. B. (2011). Exploring the molecular mechanisms of nickel-induced genotoxicity and carcinogenicity: a literature review. Reviews on environmental health, 26(2), 81-92.

Caserta, D., Graziano, A., Monte, G. L., Bordi, G., \& Moscarini, M. (2013). Heavy metals and placental fetal-maternal barrier: a mini-review on the major concerns. Eur Rev Med Pharmacol Sci, 17(16), 2198-2206.

Chagas, C. C., Guimarães, R. M., \& Boccolini, P. M. M. (2013). Câncer relacionado ao trabalho: uma revisão sistemática. Cadernos Saúde Coletiva, 21(2), 209-223.

Costa, L. S. D. (2020). Bioacumulação de metais pesados em pequenos mamíferos em áreas de remanescentes de mata atlântica e monocultura de cana-deaçúcar na Paraíba, Brasil. Trabalho de conclusão de curso - Monografia. (Graduação em Ciências Biológicas da Universidade Federal da Paraíba).

Da Costa, M. H. P., da Silva, P. C. C., \& da Rocha, C. A. M. (2016). Efeitos do cromo hexavalente sobre o crescimento de raízes e ciclo celular no meristema da ponta da raiz de Allium cepa. Biota Amazônia (Biote Amazonie, Biota Amazonia, Amazonian Biota), 6(3), 40-44.

Da Cruz M., J., \& Gonçalves, P. R. (2020). Impacto Toxicológico de Metais Pesados: Uma Análise de Efeitos Bioquímicos e Celulares: Impact of Heavy Metals: An Analysis of Biochemical and Cellular Effects. Health and Biosciences, 1(2), 88-100. 
Düsman, E., Berti, A. P., Soares, L. C., \& Vicentini, V. E. P. (2012). Principais agentes mutagênicos e carcinogênicos de exposição humana. SaBios-Revista de Saúde e Biologia, 7(2).

Ferreira, A. P., \& Wermelinger, E. D. (2013). Concentrações séricas de metais e suas implicações para a saúde pública. J. Health Sci. Inst, 31(1).

Ferreira, A. P., Horta, M. A. P., \& Cunha, C. L. N. (2010). Assessment of heavy metal concentrations in sediment, water and organs of Nycticorax nycticorax (Black-crowned Night Heron) in Sepetiba Bay, Rio de Janeiro, Brazil. J Integrat Coastal Zone Manage, 10(2), 81-93.

Ferron, M. M., Kuno, R., Campos, A. E. M. D., Castro, F. J. V. D., \& Gouveia, N. (2020). Cadmium, lead and mercury in the blood of workers from recycling sorting facilities in São Paulo, Brazil. Cadernos de Saúde Pública, 36, e00072119.

Freitas AH. (2016). Reflexões sobre a Pesquisa Acadêmica: Revisão Bibliográfica, Vivência e conhecimento. Palíndromo, 8(15), 074-082.

Gaudet, H. M., Christensen, E., Conn, B., Morrow, S., Cressey, L., \& Benoit, J. (2018). Methylmercury promotes breast cancer cell proliferation. Toxicology reports, 5, 579-584.

Guecheva, T. N. (2002). Avaliação do potencial tóxico e genotóxico do sulfato de cobre em planária: utilidade deste organismo para biomonitoramento ambiental. Tese de doutorado. (Programa de Ciências Biológicas: Bioquímica da Universidade Federal do Rio Grande do Sul).

Guimarães, R. M., Rohlfs, D. B., Baêta, K. F., \& dos Santos, R. D. (2019). Estabelecimento de agentes e atividades ocupacionais carcinogênicas prioritárias para a vigilância em saúde no Brasil. Rev. bras. med. trab, 254-259.

Kim, Y., \& Lee, B. K. (2012). Associations of blood lead, cadmium, and mercury with estimated glomerular filtration rate in the Korean general population: analysis of 2008-2010 Korean National Health and Nutrition Examination Survey data. Environmental research, 118, $124-129$.

Koedrith, P., \& Seo, Y. R. (2011). Advances in carcinogenic metal toxicity and potential molecular markers. International journal of molecular sciences, 12(12), 9576-9595

Koller, D. K., \& Reginato, P. A. R. (2017). Avaliação do risco à saúde humana por meio do consumo de água subterrânea contendo metais, na zona rural do município de Palmares do Sul (RS). Simpósio Brasileiro de Recursos Hídricos (22) Florianópolis, 2017). Anais [recurso eletrônico].[Porto Alegre: ABRH, 2017].

Kumar, V., Abbas, A. K., \& Aster, J. C. (2017). Robbins basic pathology e-book. Elsevier Health Sciences. (9a ed.).

Kuno, R., Roquetti, M. H., \& Gouveia, N. (2010). Concepts and determination of reference values for human biomonitoring of environmental contaminants. Revista Panamericana de Salud Pública, 27, 74-79.

Lee, J. C., Son, Y. O., Pratheeshkumar, P., \& Shi, X. (2012). Oxidative stress and metal carcinogenesis. Free radical biology and medicine, 53(4), 742-757.

Leite, A., Silva, R., \& Cunha, E. (2015). Occupational disease: Medico legal importante. A case report. Arquivos de Medicina, $29(4), 93-97$.

Lima, D. P. (2013) Avaliação da contaminação por metais pesados na água e nos peixes da bacia do Rio Cassiporé, estado do Amapá, Amazônia, Brasil. Dissertação de mestrado (Programa de Pós-Graduação em Biodiversidade Tropical da Universidade Federal do Amapá).

Loureiro, A. P. M., Di Mascio, P., \& Medeiros, M. H. (2002). Formação de adutos exocíclicos com bases de DNA: implicações em mutagênese e carcinogênese. Química Nova, 25(5), 777-793.

Lubovac-Pilav Z. et al. (2013). Using expression profiling to understand the effects of chronic cadmium exposure on MCF-7 breast cancer cells. PloS one. $8(12), 84646$

Magalhães, M. M. (2018). Avaliação da toxicidade aguda in vivo após exposição oral a nanopartículas de óxido de cobre, de acordo com as diretrizes do Guia 420 da OECD (Doctoral dissertation), Fundação Oswaldo Cruz, Rio de Janeiro, Instituto Nacional de Controle de Qualidade em Saúde.

Manrich, A., Hubinger, S. Z., \& Paris, E. C. (2017). Citotoxicidade causada por nanomateriais: avaliação do micronúcleo. In Embrapa Instrumentação-Artigo em anais de congresso (Alice). In: Workshop da rede de nanotecnologia aplicada ao agronegócio, 9, 2017, São Carlos. Anais... São Carlos: Embrapa Instrumentação, 2017. p. 655-658

Martinez-Zamudio, R., \& Ha, H. C. (2011). Environmental epigenetics in metal exposure. Epigenetics, 6(7), 820-827.

Meng, Y., Tang, C., Yu, J., Meng, S., \& Zhang, W. (2020). Exposure to lead increases the risk of meningioma and brain cancer: A meta-analysis. Journal of Trace Elements in Medicine and Biology, 60, 126474.

Neves, M. O. (2015). A importância da investigação qualitativa no processo de formação continuada de professores: subsídios ao exercício da docência. Revista Fundamentos, 2(1), 17-31.

Oliveira, F. L. V. (2019). Cromo em água subterrânea e mortalidade por câncer de estômago na população do Planalto Ocidental Paulista e de municípios limítrofes. Dissertação de mestrado. (Programa de Saúde Coletiva da Universidade de São Paulo).

Parodi, D. A., Greenfield, M., Evans, C., Chichura, A., Alpaugh, A., Williams, J., \& Martin, M. B. (2017). Alteration of mammary gland development and gene expression by in utero exposure to cadmium. International journal of molecular sciences, 18(9), 1939.

Paula, E. S. D. Avaliação dos efeitos tóxicos resultantes da exposição crônica a baixas doses de chumbo e metilmercúrio, associados ou não, e do possível efeito protetor da niacina diante desta exposição (Doctoral dissertation, Universidade de São Paulo).

Pavlogeorgatos, G., \& Kikilias, V. (2002). The importance of mercury determination and speciation to the health of the general population. Glob. Nest Int. J, 4, $107-125$. 
Research, Society and Development, v. 10, n. 6, e45810615992, 2021

(CC BY 4.0) | ISSN 2525-3409 | DOI: http://dx.doi.org/10.33448/rsd-v10i6.15992

Peixoto, S. V., \& Asmus, C. I. R. F. (2020). O desastre de Brumadinho e os possíveis impactos na saúde. Ciência e Cultura, 72 (2), 43-46.

Perlroth, N. H., \& Branco, C. W. C. (2017). Current knowledge of environmental exposure in children during the sensitive developmental periods. Jornal de Pediatria, 93(1): 17-27

Rehme, M. F. B., Pontes, A.G., Corrente, J. E., Franco, J. R., \& Pontes, A. (2013). Contribuição do hiperandrogenismo para o desenvolvimento de síndrome metabólica em mulheres obesas com síndrome dos ovários policísticos. Revista Brasileira de Ginecologia e Obstetrícia, 35(12), 562-568.

Rivera, K., \& Pernía, B. (2021). Determinación de los niveles de plomo en sangre en trabajadores de fábricas de baterías ubicadas en Guayaquil-Ecuador. Revista Enfoque UTE. Doi: https://doi.org/10.29019/enfoqueute.727

Roman, T. R. N., Lima, E. G., Azoubel, R., \& Batigália, F. (2002). Toxicidade do Cádmio no Homem. HB Científica, 9(1): 43-48.

Sharma, B., Singh, S., \& Siddiqi, N. J. (2014). Biomedical implications of heavy metals induced imbalances in redox systems. BioMed research international. Doi: https://doi.org/10.1155/2014/640754

Silva, C. A. \& Santos, S. O. (2016). Avaliação do Potencial Risco à Saúde Humana de Metais Pesados em Peixes Marinhos Consumidos em Aracaju, Maceió e Salvador, Brasil. Embrapa Tabuleiros Costeiros- Boletim de Pesquisa e Desenvolvimento, 22p.

Silva, G. R. R., Rudy, J. T., Matos, K. F. R., Silva, E. L., \& Gurgel, H. D. C. (2019). Análise dos possíveis efeitos na incidência de neoplasias referentes a intoxicação por metais pesados após o desastre ambiental da Samarco em Mariana-MG. In: Simpósio Nacional de Geografia da Saúde, 9, Blumenau - SC.

Souza, A. K. R., \& Morassuti, C. Y. (2018). Poluição do ambiente por metais pesados e utilização de vegetais como bioindicadores. Acta Biomedica Brasiliensia, 9(3), 95-106.

Thannickal, V. J., \& Fanburg, B. L. (2000). Reactive oxygen species in cell signaling. American Journal of Physiology-Lung Cellular and Molecular Physiology, 279(6), 1005-1028.

Zendron R. (2015). Mecanismos de neurotoxicidade e doenças neurológicas relacionadas à intoxicação por metais pesados. Revista Brasileira de Nutrição Funcional. 64(1), 45-51. 